\title{
Wonder Spray (HOCL) Kills the Bacteria that Cause Strep Throat and Pneumonia
}

\author{
John F Burd* \\ Wonder Spray, San Diego CA, USA
}

*Corresponding author: John F Burd, Wonder Spray, Llc, San Diego CA 92130 USA.

Received Date: November 16, 2019

Published Date: November 20, 2019

\begin{abstract}
The bacteria that is the cause of strep throat is Streptococcus pyogenes and one cause of pneumonia is infection with Streptococcus pneumoniae. Wonder spray is a new product with an active ingredient of Hypochlorous acid (HOCL) that has been FDA cleared for use in wound healing. HOCL is used by the body's white blood cells to kill all pathogens; bacteria, virus, yeast mold and fungus [1]. We performed a kill time study to determine if HOCL was effective in killing Streptococcus pyogenes and Streptococcus pneumoniae. We discovered that HOCL kills these bacteria with a 6-log reduction in less than 15 seconds. Healthcare professionals may wish to consider using HOCL as an alternative to standard antibiotic regimens.
\end{abstract}

\section{Procedure Summary}

This study was performed at Micro Quality Labs, Inc in Burbank California. The organisms were prepared by inoculating the surface of $5 \%$ Sheep blood agar plates, incubated at 30 to $35^{\circ} \mathrm{C}$ for 18 to 24 hours. Following the incubation period, the plates are washed with sterile Serological Saline Solution to harvest the microorganisms used and dilutions with Saline were made, plated on blood agar and incubated at 30 to $35^{\circ} \mathrm{C}$ for $24-48$ hours to determine the concentration. The inoculum level was then adjusted to $108 \mathrm{cfu} /$ $\mathrm{ml}$ for use as a stock suspension. Stock suspensions were well mixed and homogenized at each inoculation interval. The following microorganisms were used in this Kill Time Study to demonstrate the antimicrobial properties of the Wonder Spray against common pathogenic organisms: Microbiologies Kwik-Stik Streptococcus pyogenes ATCC 49399, Streptococcus pneumoniae ATCC 49619.

Positive controls were performed at initiation and completion by spread plating to enumerate inoculum levels and verify culture purity during testing and Negative controls are performed to establish sterility of media, reagents, and materials used at initiation. Neutralizer Suitability using Modified Letheen Broth (MLB) was performed concurrently with Kill Time testing to confirm the recovery of $<100 \mathrm{CFU}$ of the test organism in the subculture media in the presence of product. Duplicate $10 \mathrm{ml}$ containers for each treated specimen or material concentration was prepared, equilibrated to $25 \pm 2^{\circ} \mathrm{C}$, and $0.1 \mathrm{ml}$ of inoculum is added to each container to achieve a final concentration of $106 \mathrm{cfu} / \mathrm{ml}$.

Serial dilutions from each replicate were made at intervals of 15 second, 30 second, 1 minute and 5 minutes using $1 \mathrm{ml}$ of the inoculated test product into 9ml MLB from 1:10 to $1: 1000000$. Subsequently, $1 \mathrm{ml}$ from each dilution was spread plated on $5 \%$ Sheep Blood agar plate in duplicate, incubated at 30 to $35^{\circ} \mathrm{C}$ for 48 hours. After the incubation period, all plates were counted to determine the number of microorganisms, results are averaged and reported as $\log 10$ reductions.

\section{Data Calculation}

(Table 1, Table 2).

Table 1: Streptococcus Pneumoniae ATCC 49619.

\begin{tabular}{|c|c|c|c|c|c|c|}
\hline \multirow{2}{*}{ Exposure Time } & \multicolumn{2}{|c|}{ Concentration of Organism cfu/ml } & \multicolumn{2}{|c|}{ Percent Reduction } & \multicolumn{2}{c|}{ Log10 Reduction } \\
\cline { 2 - 7 } & Control & Product & Control & Product & Control & Product \\
\hline Initial & $1.14 \times 106$ & N/A & N/A & N/A & N/A & N/A \\
\hline Time $15 \mathrm{sec}$ & N/A & $<10$ & N/A & $99.99 \%$ & 6.057 \\
\hline
\end{tabular}




\begin{tabular}{|c|c|c|c|c|c|c|}
\hline Time $30 \mathrm{sec}$ & N/A & $<10$ & N/A & $99.99 \%$ & N/A & 6.057 \\
\hline Time 1 minute & N/A & $<10$ & N/A & $99.99 \%$ & N/A & 6.057 \\
\hline Time 5 minute & N/A & $<10$ & N/A & $99.99 \%$ & N/A & 6.057 \\
\hline
\end{tabular}

Table 2: Streptococcus Pyogenes ATCC 49399.

\begin{tabular}{|c|c|c|c|c|c|c|}
\hline \multirow{2}{*}{ Exposure Time } & \multicolumn{2}{|c|}{ Concentration of Organism cfu/ml } & \multicolumn{2}{|c|}{ Percent Reduction } & \multicolumn{2}{c|}{ Log10 Reduction } \\
\cline { 2 - 7 } & Control & Product & Control & Product & Control & Product \\
\hline Initial & $1.22 \times 106$ & N/A & N/A & N/A & N/A \\
\hline Time $15 \mathrm{sec}$ & N/A & $<10$ & N/A & $99.99 \%$ & N/A & 6.086 \\
\hline Time $30 \mathrm{sec}$ & N/A & $<10$ & N/A & $99.99 \%$ & N/A & 6.086 \\
\hline Time 1 minute & N/A & $<10$ & N/A & $99.99 \%$ & N/A & 6.086 \\
\hline Time 5 minute & N/A & $<10$ & N/A & $99.99 \%$ & N/A & 6.086 \\
\hline
\end{tabular}

\section{Conclusion}

Wonder spray (HOCL) is a powerful, yet safe, product, cleared by the FDA for wound care due to its ability to kill all pathogens. In this study, bacteria that cause strep throat and pneumonia are effectively killed by HOCL in less than 15 seconds. Healthcare professionals most often prescribe penicillin or amoxicillin to treat these bacterial infections. Side effects of penicillin antibiotics include diarrhea, dizziness, heartburn, insomnia, nausea, itching, vomiting, confusion, abdominal pain, easy bruising, bleeding, rash, and allergic reactions. The most common side effects of amoxicillin are nausea, vomiting, stomach pain and diarrhea. These are typically short-lived and resolve once you stop taking the antibiotic.

Although amoxicillin destroys infection-causing bacteria, it will also destroy the good bacteria that naturally reside in the body. This can lead to an overgrowth of yeast, which may not only produce diarrhea but also cause yeast infections, especially in the mouth and vagina. In addition, oral amoxicillin exposure caused marked shifts in microbiome composition that lasted approximately 30 days on average and were observed for more than 2 months in some of the treated individuals [2]. The additional concern about resistance to antibiotics is well known. Bacteria have not been known to develop a resistance to HOCL nor is it known to cause any of the side effects listed above. Healthcare professionals may wish to consider using HOCL in their office or recommending it to patients for use at home.

\section{Acknowledgement}

None.

\section{Conflict of Interest}

No conflict of interest.

\section{References}

1. Del Rosso, Bhatia (2018) Status Report on Topical Hypochlorous Acid: Clinical Relevance of Specific Formulations, Potential Modes of Action, and Study Outcomes. J Clin Aesthet Dermatol 11(11): 36-39.

2. Francino MP (2015) Antibiotics and the Human Gut Microbiome: Dysbioses and Accumulation of Resistances. Front Microbiol 6: 1543. 